\title{
A case-referent study of cancer mortality among sulfate mill workers in Sweden
}

\author{
E Andersson, S Hagberg, T Nilsson, B Persson, G Wingren, K Torén
}

Department of Occupational and Environmental Medicine, Sahlgrenska University Hospital, St Sigfridsgatan 85B, S-412 66 Göteborg, Sweden

E Andersson

S Hagberg

K Torén

Department of Occupational and Environmental Medicine, Sundsvall Hospital, Sundsvall, Sweden

T Nilsson

Center for Public Health Sciences, Department of Occupational and Environmental Medicine, Linköping, Sweden

B Persson

Division of Occupational and Environmental Medicine, Department of Health and Environment, Faculty of Health Sciences, Linköping, Sweden $\mathrm{G}$ Wingren

Correspondence to: Dr E Andersson eva.andersson@ymk.gu.se

Accepted 1 February 2001

\begin{abstract}
Objectives-To investigate whether workers in Swedish sulfate mills have an increased risk of death from certain malignancies that have previously been linked to the pulping process.

Methods-Subjects of the study $(n=2480)$ were men aged $40-75$ at death during 1960-89 in the parishes surrounding four sulfate mills. Exposure assessment was based on information from the personnel files in the mills- $35 \%$ of the subjects were recognised there, and work categories were created.

Results-Among all sulfate mill workers, the odds ratio (OR) $(90 \%$ confidence interval (90\% CI)) for death from lung cancer was 1.6 (1.1 to 2.3$)$, pleural mesotheliomas 9.5 (1.9 to 48 ), brain tumours 2.6 (1.2 to 5.3), and liver or biliary tract cancer 2.3 (1.0 to 5.2). There was an increased mortality from leukaemia among workers in the soda recovery plant (5.9 (2.6 to 13)) and bleaching plant and digester house $(2.8$ (1.0 to 7.5$))$.

Conclusions-Sulfate mill workers were at increased risk of dying from lung cancer and pleural mesotheliomas, probably due to exposure to asbestos. Increased risks of brain tumours and cancers of the liver or biliary tract were also found but the aetiology is not obvious.

(Occup Environ Med 2001;58:321-324)
\end{abstract}

Keywords: epidemiology; pulp and paper industry; brain neoplasm

Two main processes can be distinguished in the production of pulp and paper, the acidic sulfite process and the more common alkaline sulfate (Kraft) process. ${ }^{1}$ The predominant chemicals in the alkaline process are a mixture of sodium hydroxide and sodium sulfide. The sulfate pulp is brownish and was earlier mostly bleached with chlorine, chlorine dioxide, hypochlorite, and sodium hydroxide in different bleaching stages. ${ }^{2}$ The main occupational exposures in sulfate mills are hydrogen sulfide, and other

Table 1 Exposure frequency and number of men who died 1960-89 aged 40-75 in each parish surrounding four Swedish sulfate mills

\begin{tabular}{llcl}
\hline Parish & Exposed (\%) & Exposed (n) & Unexposed (n) \\
\hline A+B & 15.7 & 45 & 241 \\
C & 55.7 & 226 & 180 \\
D & 30.5 & 392 & 894 \\
E & 39.0 & 196 & 306 \\
\hline
\end{tabular}

reduced sulfur compounds, wood dust, terpenes, and bleaching chemicals. ${ }^{1}$ The maintenance workers in pulp mills (and paper mills), independently of the type of process, have also been exposed to asbestos. ${ }^{13}$

Despite the fact that the exposures are different to some extent, most previous epidemiological studies on pulp mills have not separated different kinds of pulping processes. ${ }^{4}$ More recent studies, however, have reported data on cancer risk among sulfate mill workers. Increased risks for stomach cancer, haematological malignancies, lung cancer, colon cancer, and kidney cancer have been reported among sulfate workers, ${ }^{4-7}$ but the results are inconsistent. Among Swedish cellulose plant workers increased risk of gliomas have been found. ${ }^{8}$

The aim of this case-referent study was to investigate whether sulfate mill workers had increased risks of mortality from different malignancies, especially lung cancer, stomach cancer, brain tumours, and haematological malignancies.

\section{Materials and methods}

THE MILLS

Four sulfate mills were selected for the study. They were in small towns in rural areas of Sweden and were the dominant industries in the regions. To our knowledge these mills have not been the subject of any other published study. A separate sawmill for production of sawn timber had been connected to three of the pulp mills, and some workers had worked both in the sawmill and in the pulp mill. Two of the mills also had a paper mill and a third mill started paper milling in 1972. Three of the mills had a bleaching plant, which started in 1932, 1946, and 1955, where chlorine dioxide was the most important bleaching agent.

\section{SUBJECTS}

Subjects for the study ( $n=2480)$, cases and referents, were obtained from the local registers of deaths and burials in five parishes, each surrounding a sulfate mill (for one mill two small parishes). The causes of death found in the registers were based on the information from death certificates. The study was restricted to men who were 40-75 when they died between 1960 and 1989. Men over 75 were excluded as the validity of the causes of death was considered to be lower in this age group than at younger ages.

The underlying cause of death was classified according to the international classification of diseases 8th revision (ICD-8). If cancer was reported on the death certificates it was always 
Table 2 Cancer mortality among male workers in Swedish sulfate mills who died in 1960-89 (odds ratios are given for all workers and those with more then 10 years employment)

\begin{tabular}{|c|c|c|c|c|c|c|c|}
\hline \multirow[b]{2}{*}{ Cancer site } & \multicolumn{3}{|l|}{ Cases (n) } & \multicolumn{2}{|c|}{ All exposed $>1 y$} & \multicolumn{2}{|c|}{$\begin{array}{l}\text { Only those exposed } \\
>10 y\end{array}$} \\
\hline & $\begin{array}{l}\text { Unexposed } \\
(n=1621)\end{array}$ & $\begin{array}{l}\text { All exposed } \\
>1 y \\
(n=859)\end{array}$ & $\begin{array}{l}\text { Only those exposed } \\
>10 \text { y }(n=640)\end{array}$ & $O R_{(M-H)}$ & $90 \% C I$ & $O R_{(M-H)}$ & $90 \% C I$ \\
\hline Stomach or oesophagus & 70 & 44 & 32 & 1.1 & 0.8 to 1.6 & 1.1 & 0.8 to 1.6 \\
\hline Liver or biliary tract & 9 & 8 & 5 & 2.3 & 1.00 to 5.2 & 2.1 & 0.9 to 5.2 \\
\hline Lung & 41 & 32 & 26 & 1.6 & 1.05 to 2.3 & 1.7 & 1.1 to 2.6 \\
\hline Pleural mesotheliomas ${ }^{\star}$ & 1 & 5 & 5 & $9.5^{\star}$ & 1.9 to 48 & $12.8^{\star}$ & 2.5 to 65 \\
\hline Brain & 10 & 12 & 9 & 2.6 & 1.2 to 5.3 & 2.6 & 1.1 to 5.7 \\
\hline Lymphomas & 16 & 8 & 6 & 0.9 & 0.4 to 2.0 & 0.9 & 0.3 to 2.1 \\
\hline Leukaemias & 24 & 9 & 6 & 0.7 & 0.4 to 1.4 & 0.6 & 0.3 to 1.4 \\
\hline
\end{tabular}

${ }^{\star}$ Crude odds ratio.

The Mantel-Haenszel odds ratio $\left(\mathrm{OR}_{(\mathrm{M}-\mathrm{H})}(90 \% \mathrm{CI})\right)$ were stratified for age and mill.

classified as underlying cause. All cancer cases were checked against the Swedish Cancer Registry, and for haematological malignancies, cancer of the liver or biliary tract, and brain tumours hospital files were also scrutinised.

Finally included in the study were cases of cancer of the stomach or oesophagus (ICD-8 $151, \mathrm{n}=114$ ), cancer of the liver or biliary tract (ICD-8 155-56, $\mathrm{n}=17$ ), lung cancer (ICD-8 162, $n=73$ ), pleural mesotheliomas (ICD-8 $163, n=6)$, brain tumours (ICD-8 192, $n=22$ ), unspecified abdominal cancer (ICD-8 195.01, $\mathrm{n}=10$ ), lymphomas (ICD-8 200-02, $\mathrm{n}=24$ ), and leukaemias (ICD-8 204-07, $\mathrm{n}=33$ ).

For each set of cases, all non-cases were used as referents - for example, for the cases of lung cancer, all other subjects (including other sets of cases) were used as referents.

\section{EXPOSURE CLASSIFICATION}

The exposure classification was based on the personnel files found in each pulp mill. According to information from these files, all subjects were classified as either exposed-the subject was found in the files as a blue collar worker-or unexposed. A minimum period of employment of 1 year was required to be classified as exposed. The classification was made without knowledge of whether the subject was a case or a referent. Out of 2480 subjects, 859
(35\%) were classified as exposed. The distribution between the different parishes is shown in table 1.

The occupationally exposed people were further subdivided into six categories; maintenance workers $(n=299)$, wood room workers $(n=121)$, sawmill workers $(n=234)$, bleaching plant and digester house workers $(n=74)$, soda recovery plant workers $(n=61)$, and others $(n=214)$. In the category others $38 \%$ were mechanical workshop workers, $21 \%$ paper mill workers, $16 \%$ causticising department workers, and $13 \%$ electricians. Of the maintenance workers one third were mechanics, the remaining were odd job men assisting in different types of maintenance work. The six categories were not mutually exclusive; hence, a person could belong to more than one category during his period of employment. Ninety nine workers belonged to two and 20 to more than two categories. Of the cancer cases, 29 workers belonged to two or more subgroups. Employment time has been calculated but the date of leaving the mill was missing for 123 workers (in the files for more than 1 year), who were left out in analyses when using employment time. Mean employment time was 24 years and $82 \%$ had been employed for more than 10 years.

Table 3 Cancer mortality among occupational subgroups of male workers in Swedish sulfate mills

\begin{tabular}{|c|c|c|c|c|c|c|}
\hline \multirow[b]{2}{*}{$\begin{array}{l}\text { Cancer site } \\
\text { (number of all cases) }\end{array}$} & \multicolumn{6}{|c|}{ Occupational subgroup (number of exposed cases) } \\
\hline & $\begin{array}{l}\text { Maintenance workers } \\
n=299\end{array}$ & $\begin{array}{l}\text { Wood room workers } \\
n=121\end{array}$ & $\begin{array}{l}\text { Sawmill workers } \\
n=234\end{array}$ & $\begin{array}{l}\text { Bleaching plant/ } \\
\text { Digester house } n=74\end{array}$ & $\begin{array}{l}\text { Soda recovery plant } \\
n=61\end{array}$ & $\begin{array}{l}\text { Others } \\
n=214\end{array}$ \\
\hline \multicolumn{7}{|c|}{$\begin{array}{l}\text { Stomach or oesophagus } \\
\quad(n=114) \text { : }\end{array}$} \\
\hline $\mathrm{n}$ & 18 & 5 & 14 & 0 & 2 & 12 \\
\hline OR & 1.4 & 0.9 & 1.4 & & & 1.3 \\
\hline $90 \% \mathrm{CI}$ & 0.9 to 2.2 & 0.4 to 2.0 & 0.9 to 2.3 & & & 0.8 to 2.2 \\
\hline \multicolumn{7}{|l|}{ Lung $(n=73)$ : } \\
\hline $\mathrm{n}$ & 12 & 4 & 10 & 3 & 2 & 7 \\
\hline OR & 1.6 & 1.3 & 1.7 & 1.6 & & 1.3 \\
\hline $90 \% \mathrm{CI}$ & 0.9 to 2.8 & 0.6 to 3.1 & 0.96 to 3.1 & 0.6 to 4.3 & & 0.7 to 2.6 \\
\hline \multicolumn{7}{|l|}{ Brain $(n=22)$ : } \\
\hline $\mathrm{n}$ & 6 & 3 & 5 & 0 & 0 & 2 \\
\hline OR & 3.3 & 4.1 & 3.5 & & & \\
\hline \multirow{2}{*}{\multicolumn{7}{|c|}{ Lymphomas $(n=24)$ : }} \\
\hline & & & & & & \\
\hline n & 4 & 3 & 1 & 0 & 1 & 2 \\
\hline OR & 1.4 & 2.5 & & & & \\
\hline $90 \% \mathrm{CI}$ & 0.6 to 3.3 & 0.9 to 6.9 & & & & \\
\hline \multicolumn{7}{|l|}{ Leukaemias $(n=33)$ : } \\
\hline $\mathrm{n}$ & 3 & 0 & 1 & 3 & 5 & 2 \\
\hline OR & 0.7 & & & 2.8 & 5.9 & \\
\hline $90 \% \mathrm{CI}$ & 0.3 to 1.8 & & & 1.04 to 7.5 & 2.6 to 13 & \\
\hline
\end{tabular}

ORs $(90 \% \mathrm{CIs})$ are crude.

Values were not analyzed when there were less then three exposed cases. 
STATISTICAL METHODS

The statistical analyses were based on the method of Mantel and Haenszel ${ }^{9}$ and the principles outlined by Axelson. ${ }^{10}$ When calculating the Mantel-Haenszel odds ratios $\left(\mathrm{OR}_{(\mathrm{M}-\mathrm{H})}\right)$, the subjects were stratified according to age (40-65 and 66-75) and parish. The SAS statistical software package (release 6.12; Cary, NC, USA) was used for statistical analyses. For occupational subgroups and when there were few cases, the crude ORs are given. Only ORs based on three or more exposed cases are tabulated. The different exposed subgroups have been compared with the men classified as unexposed.

\section{Results}

Sulfate mill workers had an increased risk of mortality from lung cancer, pleural mesotheliomas, brain tumours, and cancer of the liver or biliary tract (table 2). If analyses were restricted to workers with more than 10 years of employment (table 2), the risk for pleural mesotheliomas increased. Stratification for calendar period of exposure or restriction to a latency period of at least 20 years did not substantially change the estimates, nor did the use of three age strata. There was also an increased risk of unspecified abdominal cancer $(n=10$, OR 4.4, $90 \%$ CI 1.5 to 13 ), which may be due to peritoneal mesotheliomas.

The ORs for different occupational categories are shown in table 3. An increased risk of death from brain tumours was found among maintenance workers, wood room workers, and sawmill workers. There was an increased risk of mortality from leukaemia among bleaching plant and digester house workers (OR 2.8, 90\% CI 1.0 to 7.5 ) and soda recovery plant workers (OR 5.9, 90\% CI 2.6 to 13). Wood room workers had the highest risk of dying from lymphomas (OR 2.5, 90\% CI 0.9 to 6.9 ).

\section{Discussion}

In the present study, an increased mortality risk from lung cancer, pleural mesotheliomas, brain tumours, and cancer of the liver or biliary tract was found among male sulfate mill workers. There was an increased risk of death from leukaemia among soda recovery plant workers and bleaching plant and digester house workers. Maintenance workers, wood room workers, and sawmill workers had an increased mortality from brain tumours.

The exposure assessment in this study was based on information from the personnel files in the mills. As stated previously, the advantage of such records is the prospective way of collecting exposure data, before onset of disease. ${ }^{11}$ Hence, the occupational information based on the files of the mills is free from observation bias relative to the outcome of disease. However, there are several limitations in the files-such as lack of information about exposure to specific agents and incomplete information about the period of employment. These shortcomings could be regarded as causing non-differential misclassification of exposure, which would result in bias towards unity.
There could be limitations with using deceased people as the source population. If the mortality from other diseases (among controls) is influenced by exposure this would effect the relative risk. For example, if the exposed men had a risk of excess mortality from cardiovascular diseases, this would attenuate the risk of cancer among the exposed population. Shift work, which is common among mill workers, could be such a factor but there was no increased mortality from cardiovascular diseases among these sulfate mill workers.

The limited study population does not permit multiple stratification for several potential confounding factors at the same time. But we have done analyses on one factor at a time and with one exception there was no change in the risk estimates. Adjusting for parish and thereby mill had a minor effect of the estimates of cancer of the liver or biliary tract and the brain. This could imply that there might be differences in exposure among the mills. In the final analysis we stratified for age (two strata) and parish.

The risk of lung cancer was increased among all workers and in different subgroups. There was also a high risk of pleural mesotheliomas in the whole group. Four of the five exposed cases of mesothelioma had worked in the building and maintenance department. These findings further underline the importance of considering asbestos as an occupational exposure among pulp mill workers. ${ }^{3}$ Differences in exposure to asbestos could be one of the reasons why some earlier studies have found an excess risk of lung cancer and some have not. From two recent large cohort studies Band et al reported the standardised mortality ratio (SMR) for lung cancer to be 1.00 (90\% CI 0.87 to 1.14 ) for sulfate mill workers ${ }^{5}$ and Matanoski et al found a relative risk of 1.35 (95\% CI 1.04 to 1.75 ) among sulfate workers compared with other pulp and paper mill workers. ${ }^{6}$

Smoking can be a confounder in lung cancer. The smoking habits of the subjects are not known in this study, but in a similar mill town the prevalence of male ever-smokers was $54 \%$, compared with $67 \%$ among the male pulp mill workers. ${ }^{12}$ Assuming these smoking habits for the present study population, we can adjust for the confounding according to Axelson. ${ }^{13}$ The relative risk of lung cancer among sulfate mill workers would then decrease from 1.6 to 1.3 , assuming the relative risk of lung cancer for ever-smokers to be 11.9. ${ }^{14}$

Brain cancer was increased among all sulfate mill workers and also among different subgroups. Of interest is that some recent studies have indicated an increased risk of brain tumours in this type of industry. In a cohort study from British Columbia, Canada, the risk of central nervous system neoplasms was increased among the sulfite workers (SMR 1.7, $90 \%$ CI 1.1 to 2.6 ), but not among the sulfate workers (SMR $0.8,90 \%$ CI 0.5 to 1.2 ). ${ }^{4}$ We have earlier found an increased risk among sulfite mill workers (OR 3.3, 90\% CI 1.1 to 8.9). ${ }^{15}$ In an older Swedish register study, pulp 
mill workers were at increased risk of developing gliomas. ${ }^{8}$ The established risk factors, inherited predisposition, and ionising radiation, are only responsible for a small fraction of brain tumours. Occupational exposures that have been associated with increased risks are organic solvents, vinyl chloride, pesticides, and polycyclic aromatic hydrocarbons, as well as non-ionising radiation. ${ }^{16}{ }^{17}$

There was no increased risk of malignant lymphomas among all sulfate mill workers in this study, but previous studies have found an increased risk in sulfite, sulfate, and unspecified pulp mill workers. ${ }^{45}$ There is support in the literature for an association between wood related work and lymphomas, ${ }^{4}$ and the present study indicates an increased risk, albeit not significant, among the wood room workers (OR 2.5, $90 \%$ CI 0.9 to 6.9 ). However, sawmill workers had no increased risk. In these mills we assess the exposure to terpenes to be considerably higher among the wood room workers.

Studies of leukaemia among pulp mill workers have limited power due to the low prevalence of the disease. However, studies with more than five cases have indicated an increased risk. ${ }^{6}{ }^{18-21}$ In the present study, we did not find an increased risk of leukaemia among all sulfate workers but when analyzing occupational subgroups there was an increased risk among bleaching plant workers (OR 2.8, 90\% CI 1.04 to 7.5$)$ and soda recovery plant workers (OR 5.9, 90\% CI 2.6 to 13). The leukaemias were both of chronic lymphatic and acute myeloic types. One possible exposure in the soda recovery plant may be to polycyclic aromatic hydrocarbons. An increased risk of haematological malignancies was found in a case-control study among people exposed to aromatic hydrocarbons (OR 2.15, 95\% CI 1.4 to 3.3), as well as an increased risk of acute non-lymphoblastic leukaemia (OR 5.28, 95\% CI 2.1 to 14$).{ }^{22}$ Bleaching workers are exposed not only to chlorine, but also to chlorinated dibenzodioxins. ${ }^{1}$ An increased risk of leukaemia has been described after exposure to 2,3,7,8-tetrachlorodibenzodioxin. ${ }^{23}$ But other mill workers could also be exposed to such chlorinated compounds.

In a recent study from British Columbia, excess mortality from cancer of the gall bladder was found among workers employed in both sulfate and sulfite processes. ${ }^{5}$ An increased incidence of cancer of the gall bladder has also been found among paper mill workers in Sweden. ${ }^{24}$ The present study indicated an increased risk of cancer of the liver or biliary tract (including gall bladder) among the sulfate workers.

There are conflicting results on the risk of stomach cancer among pulp mill workers, ${ }^{4}$ and the recent cohort studies have not found an increase among sulfate mill workers. ${ }^{56}$ The present study showed a risk close to unity.
In conclusion, workers in these four Swedish sulfate mills are at increased risk of developing lung cancer and pleural mesotheliomas, probably caused by exposure to asbestos. They also had increased risks for brain tumours and cancer of the liver or biliary tracts but the reason for that is not obvious. Further studies should try to elucidate the exposures causing these increased risks.

The study was supported by the Swedish Council for Worklife Research and Emil Anderssons' Research Fund.

1 Torén K, Hagberg S, Westberg H. Health effects of working in pulp and paper mills: exposure, obstructive airways diseases, hypersensitivity reactions, and cardiovascular diseases. Am F Ind Med 1996;29:111-22.

2 Torén K, Blanc P. The history of pulp and paper bleaching: respiratory-health effects. Lancet 1997;349:1316-8.

3 Järvholm B, Malker H, Malker B, et al. Pleural mesotheliomas and asbestos exposure in the pulp and paper industries: a new risk group identified by linkage of official registers. Am f Ind Med 1988;13:561-7.

4 Torén K, Persson B, Wingren G. Health effects of working in pulp and paper mills: malignant diseases. Am f Ind Med 1996;29:123-30.

5 Band PR, Le ND, Fang R, et al. Cohort mortality study of pulp and paper mill workers in British Columbia, Canada. Am F Epidemiol 1997;146:186-94.

6 Matanoski GM, Kanchanaraksa S, Lees PSJ, et al. Industrywide study of mortality of pulp and paper mill workers. Am f Ind Med 1998;33:354-65.

7 Sala-Serra M, Sunyer J, Kogevinas M, et al. Cohort study on cancer mortality among workers in the pulp and paper industry in Catalonia, Spain. Am f Ind Med 1996;30:8792.

8 McLaughlin JK, Malker HSR, Blot WJ, et al. Occupational risks for intracranial gliomas in Sweden. $\mathcal{F}$ Natl Cancer Inst 1987;78:253-7.

9 Mantel N, Haenszel W. Statistical aspects of the analysis of data from retrospective studies of disease. F Natl Cancer Inst 1959;232:719-48.

10 Axelson O. Elucidation of some epidemiologic principles. Scand $\mathcal{F}$ Work Environ Health 1983;9:231-40.

11 Correa A, Stewart WF, Yeh H-C, et al. Exposure measurement in case-control studies: reported methods and recommendations. Epidemiol Rev 1994;16:18-31.

12 Stjernberg N. Chronic bronchitis and bronchial asthma in an industrial community in northern Sweden. Relation to environmental and occupational exposure to $\mathrm{SO}_{2}$ [Thesis]. Umeå, Sweden: Department of Lung Medicine, University of Umeå, 1985 .

13 Axelson O. [Letter to the editor]. Scand $\mathcal{F}$ Work Environ Health 1978;4:98-102.

14 Prescott E, Osler M, Hein HO, et al. Gender and smoking related risk of lung cancer. Epidemiology 1998;9:79-83.

15 Andersson E, Nilsson T, Persson B, et al. Mortality from asthma and cancer among sulfite mill workers. Scand $\mathcal{F}$ Work Environ Health 1998;24:12-7.

16 Inskip PD, Linet MS, Heineman EF. Etiology of brain tumors in adults. Epidemiol Rev 1995;17:382-414.

17 Kheifets LI, Afifi AA, Buffler PA, et al. Occupational electric and magnetic field exposure and brain cancer: a metaanalysis. F Occup Environ Med 1995;37:1327-41.

18 Milham S Jr, Demers RY. Mortality among pulp and paper workers. f Occup Med 1984;26:844-6.

19 Wingren G, Persson B, Thorén K, et al. Mortality pattern among pulp and paper mill workers in Sweden: a case-referent study. Am F Ind Med 1991;20:769-74.

20 Milham S Jr. Neoplasia in the wood and pulp industry. Ann NY Acad Sci 1976;271:294-300.

21 Schwartz E. A proportionate mortality ratio analysis of pulp and paper mill workers in New Hampshire. $\operatorname{Br} \mathcal{F}$ Ind Med 1988;45:234-8

22 Pasqualetti P, Casale R, Colantonio D, et al. Occupational risk for hematological malignancies. Am $\mathcal{f}$ Hematology 1991;38:147-9.

23 Bertazzi PA, Zocchetti C, Pesatori AC, et al. Mortality of a young population after accidental exposure to $2,3,7,8-$ tetrachlorodibenzodioxin. Int $\mathcal{F}$ Epidemiol 1992;21:118-23.

24 Malker HSR, McLaughlin JK, Malker BK, et al. Biliary tract cancer and occupation in Sweden. $\mathrm{Br} \mathcal{F}$ Ind $\mathrm{Med}$ 1986;43:257-62. 